\title{
Evaluation of Relative Sensitivity Factors for Elemental Analysis of Aluminum and Magnesium Using Glow Discharge Mass Spectrometry with a Fast-Flow Grimm-type Ion Source
}

\author{
Kentaro YAMADA ${ }^{* \dagger}$ and Michihisa Uemoto** \\ * Jonan Branch, Tokyo Metropolitan Industrial Technology Research Institute, 1-20-20 Minami-kamata, Ota, \\ Tokyo 144-0035, Japan \\ **School of Science and Engineering, Meisei University, 2-1-1 Hodokubo, Hino, Tokyo 191-8506, Japan
}

\begin{abstract}
Relative sensitivity factors on glow discharge mass spectrometry were evaluated for unalloyed and alloyed metals of aluminum and magnesium using a glow discharge mass spectrometer operated with fast flow Grimm-type source. All the elements measured could be classified into two groups, i.e. a group of elements could be determined with repeatability equal to or less than $15 \%$ relative standard deviation, while another group could be determined with RSDs of greater than $15 \%$. The latter is mainly due to the instability of discharge condition and elemental segregation onto certified reference materials.
\end{abstract}

Keywords Glow discharge mass spectrometry, relative sensitivity factor, fast-flow grimm-type source, aluminum, magnesium

(Received February 27, 2018; Accepted April 6, 2018; Published June 10, 2018)

\section{Introduction}

Glow discharge mass spectrometry (GD-MS) is an excellent analytical technique capable of determining trace elements in solids directly and speedily. In addition to the original ion source using a direct insertion probe, ${ }^{1}$ a Grimm-type source to improve sample throughput and to retrieve time of measurement has been devised. ${ }^{2,3}$ It is more effective for elemental sensitivity if the source is operated with a fast gas flow rate. ${ }^{3}$

A relative sensitivity factor (RSF), which is defined by an ion beam ratio (IBR) of the analyte element to the matrix element, and the corresponding elemental concentration are important instrumental characteristics of GD-MS to be utilized for determination. Semi-quantitative analysis is accordingly practicable in any matrix once the RSFs are obtained using certified reference materials (CRMs) of $\mathrm{Fe}$ in advance, which is characterized as "standard RSF". ${ }^{4}$ However, the RSF values obtained experimentally with CRMs of corresponding matrix elements is preferable for more reliable quantification.

In this work, the RSF values in two metal matrices of $\mathrm{Al}$ and $\mathrm{Mg}$ alloys are experimentally measured with their CRMs using a Grimm-type source GD-MS. These light metals have been widely applied in manufacturing, and highly purified metals are not only needed for transport and mobile apparatus industries but also for electrical and semiconductor device industries. The $\mathrm{RSF}$ of trace elements in $\mathrm{Al}$ and $\mathrm{Mg}$ matrices have previously been investigated using the conventional GD-MS, ${ }^{5,6}$ but those with a Grimm-type source GD-MS, which is a fast and sensitive up-to-date model, have not been well evaluated until now.

The number of the CRMs used and the elements measured

† To whom correspondence should be addressed.

E-mail: yamada.kentaro@iri-tokyo.jp were 10 and 26 for the $\mathrm{Al}$ matrix and 7 and 19 for the $\mathrm{Mg}$ matrix, respectively.

\section{Experimental}

Apparatus and discharge conditions

All the measurements in this work were carried out with a Grimm-type GDMS named ELEMENT-GD (Thermo Fisher Scientific, MA, USA). This modern GD-MS is equipped with a fast flow DC ion source. ${ }^{3}$ The optimized glow-discharge conditions and instrument settings are shown in Table 1, where the main discharge parameters were discharge current and argon carrier gas flow rate, maintained at $72.5 \mathrm{~mA}$ and $450 \mathrm{ml} / \mathrm{min}$, respectively, throughout the measurements. Mass resolution $(R)$

Table 1 The apparatus and the discharge conditions

\begin{tabular}{ll}
\multicolumn{1}{c}{$\begin{array}{c}\text { Glow discharge mass } \\
\text { spectrometer }\end{array}$} & \multicolumn{1}{c}{ Element GD } \\
\hline Mass resolution & 4500 \\
Glow discharge & Constant direct current \\
Diameter of discharge spot & $8 \mathrm{~mm}$ \\
Discharge current & $72.5 \mathrm{~mA}$ \\
Discharge gas & $\mathrm{Ar}(99.999 \%)$ \\
Gas flow rate & $450 \mathrm{ml} / \mathrm{min}$ \\
Sputtering rate of sample & $\sim 6 \mu \mathrm{m} / \mathrm{min}$ \\
Pre-sputtering time & $5 \mathrm{~min}$ \\
Scanning time & $5 \mathrm{~min}$ \\
Anode material & Highly pure graphite carbon \\
Pretreatment for sample & Dry turning by WC tips $\left(R_{\mathrm{a}}=1\right.$ to $\left.5 \mu \mathrm{m}\right)$ \\
surface & \\
\hline
\end{tabular}


was selected at medium resolution of approximately $R=4500$ according to $5 \%$ valley definition, ${ }^{8}$ but low $(R=300)$ and high $(R=10000)$ resolutions were also used, taking sensitivity and spectral interferences into consideration. The times of presputtering and measurement were both $5 \mathrm{~min}$, and repetition of data acquisition in each measurement was five.

Calculation of the relative sensitivity factor

The RSF values of the analyte were evaluated from the IBR and a certified mass fraction value as follows ${ }^{2}$

$$
w_{\mathrm{M}}^{\mathrm{A}}=\mathrm{IBR}_{\mathrm{M}}^{\mathrm{A}} \times \mathrm{RSF}_{\mathrm{M}}^{\mathrm{A}}
$$

where $w_{\mathrm{M}}^{\mathrm{A}}$ is the mass fraction of analyte $\mathrm{A}$ in matrix $\mathrm{M}, \mathrm{IBR}_{\mathrm{M}}^{\mathrm{A}}$ is an IBR of analyte $A$ to matrix $M$, and $\operatorname{RSF}_{M}^{A}$ is a relative sensitivity factor of the analyte $\mathrm{A}$ in the matrix $\mathrm{M}$.

\section{Samples}

Aluminum and $\mathrm{Mg}$ alloy CRMs were used for all the measurements. Table 2 lists the chemical composition of CRMs of $\mathrm{Al}$ alloys purchased from Alcan. The Al CRMs are correspondingly named to a series of wrought $\mathrm{Al}$ and $\mathrm{Al}$ alloys designated in the 1000 to 7000 series in the ISO standard.? Table 2 lists those of the CRMs of $\mathrm{Mg}$ alloys purchased from MBH Analytical Ltd. The Mg CRMs used were partly based on

Table 2 The CRMs used in this work

\begin{tabular}{|c|c|c|c|}
\hline $\begin{array}{l}\text { Al CRM } \\
\text { (Alcan) }\end{array}$ & $\begin{array}{l}\text { Aluminum } \\
\text { alloy series }\end{array}$ & $\begin{array}{l}\mathrm{Mg} \text { CRM } \\
(\mathrm{MBH})\end{array}$ & $\begin{array}{l}\text { Magnesium } \\
\text { alloy series }\end{array}$ \\
\hline $136 / 02$ & Aluminum (1000 series) & 61X MGP5 & Magnesium \\
\hline 141/01 & Aluminum (1000 series) & 61X MGP6 & Magnesium \\
\hline $215 / 01$ & Al-Cu alloy (2000 series) & 65X MGA16 & $\begin{array}{l}\text { Mg-Al-Zn alloy } \\
\text { (AZ series) }\end{array}$ \\
\hline $321 / 01$ & Al-Mn alloy (3000 series) & $65 \mathrm{X}$ MGB2 & $\begin{array}{c}\mathrm{Mg}-\mathrm{Al}-\mathrm{Zn} \text { alloy } \\
\text { (AZ series) }\end{array}$ \\
\hline $441 / 03$ & Al-Si alloy (4000 series) & 66X MGC4 & $\begin{array}{l}\text { Mg-Zn alloy } \\
\text { (ZK series) }\end{array}$ \\
\hline $514 / 02$ & Al-Mg alloy (5000 series) & 66X MGD1 & $\begin{array}{l}\text { Mg-Zn alloy } \\
\text { (ZK series) }\end{array}$ \\
\hline $532 / 01$ & Al-Mg alloy (5000 series) & 63X MGE2 & $\begin{array}{l}\text { Mg-Mn alloy } \\
\text { (M series) }\end{array}$ \\
\hline $533 / 03$ & Al-Mg alloy (5000 series) & & \\
\hline $636 / 02$ & Al-Mg-Si alloy (6000 series) & & \\
\hline $724 / 02$ & Al-Zn-Mg alloy (7000 series) & & \\
\hline
\end{tabular}

(a) Group of elements (RSD $<15 \%$ ) $\mathrm{Si}, \mathrm{Fe}, \mathrm{Cu}, \mathrm{Mn}, \mathrm{Mg}, \mathrm{Cr}, \mathrm{Ni}, \mathrm{Zn}, \mathrm{V}$ etc.

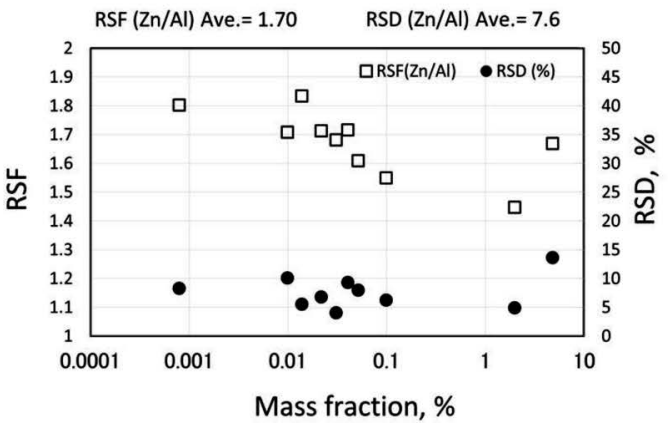

the ISO standard ${ }^{8}$ in chemical composition but their coding was somewhat free from designation. They could be classified into $\mathrm{Mg}-\mathrm{Al}, \mathrm{Mg}-\mathrm{Zn}$, and $\mathrm{Mg}-\mathrm{Mn}$ alloys.

\section{Results and Discussion}

To check the sampling depth on the glow discharge condition, after sputtering of the CRM (Alcan 724/02 in Table 2) for 10 min, a crater shape was measured and is shown in Fig. 1. Measuring an averaged depth in the crater, the sputtering rate is approximately $6 \mu \mathrm{m} / \mathrm{min}$.

For all elements measured in this work, a correlation between the obtained RSF values and element concentrations was investigated. RSF values in the $\mathrm{Al}$ and $\mathrm{Mg}$ matrices were almost steady and seemed to have no correlation. Representative results in the $\mathrm{Al}$ matrix are shown in Fig. 2. In the results for $\mathrm{Zn}$ in the Al matrix shown in Fig. 2(a), the obtained RSF value is steady within the concentration range measured and its relative standard deviation (RSD) values were below $15 \%$. Other elements classified into this group were $\mathrm{Si}, \mathrm{Fe}, \mathrm{Cu}, \mathrm{Mn}, \mathrm{Mg}, \mathrm{Cr}$, $\mathrm{Ni}$, and $\mathrm{V}$. In contrast, the RSF value for $\mathrm{Pb}$ in the $\mathrm{Al}$ matrix shown in Fig. 2(b) exhibits intense dispersion and the RSD values were almost above $15 \%$. Titanium, $\mathrm{Sn}$, and $\mathrm{Zr}$ could be listed as similar elements. Thus, measured elements were classified into two groups in view of the RSF values obtained.

An almost similar tendency was recognized in the measurement of the $\mathrm{Mg}$ matrix. The RSF values for $\mathrm{Zn}$ in the $\mathrm{Mg}$ matrix are

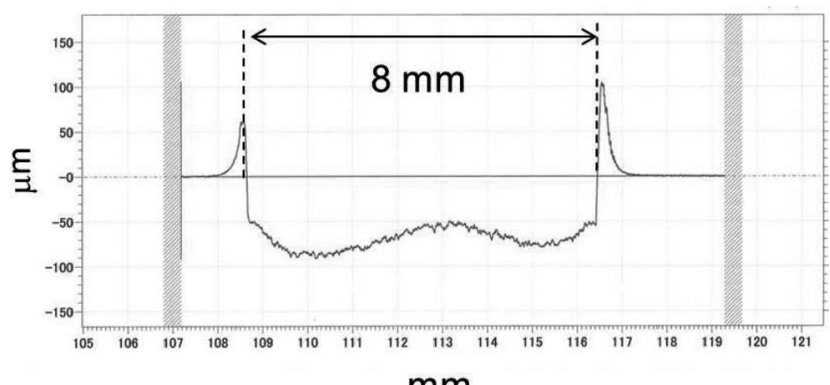

$\mathrm{mm}$

Fig. 1 The profile of crater surface of sample after GD-MS analysis (Alcan CRM 724/02).

\section{(b) Group of elements (RSD > 15\%) \\ $\mathrm{Ti}, \mathrm{Pb}, \mathrm{Sn}, \mathrm{Zr}$ etc.}

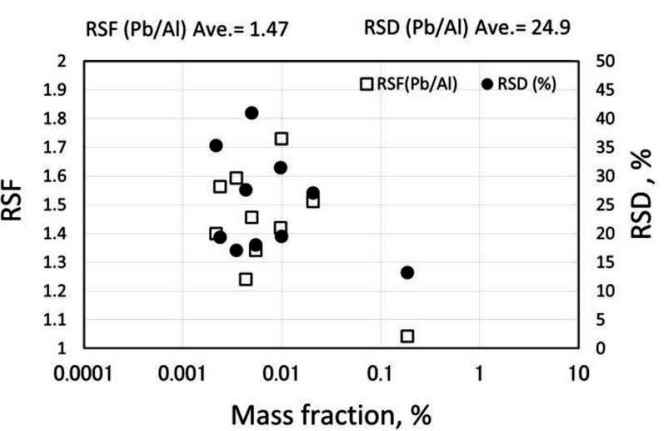

Fig. 2 Tendency of RSF values and RSD in Al alloys. (a) Zn (typical element of RSD $<15 \%$ ), (b) Pb (typical element of RSD >15\%). 
(a) Group of elements (RSD < 15\%)

$\mathrm{Al}, \mathrm{Si}, \mathrm{Ti}, \mathrm{Mn}, \mathrm{Fe}, \mathrm{Ni}, \mathrm{Cu}, \mathrm{Ni}, \mathrm{Zn}, \mathrm{Ag}, \mathrm{Cd}$ etc.

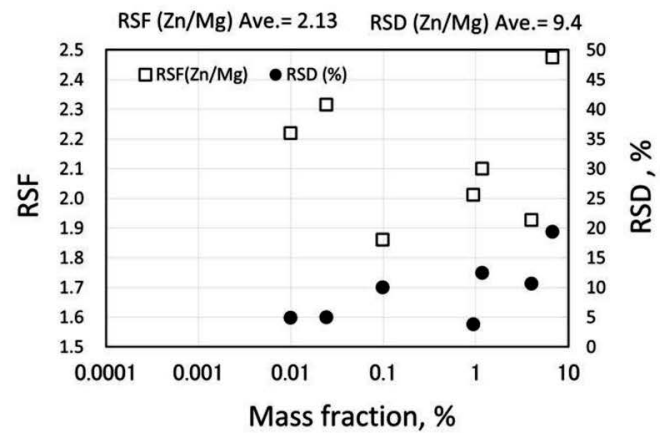

(b) Group of elements (RSD > 15\%)

$\mathrm{Y}, \mathrm{Sn}, \mathrm{La}, \mathrm{Ce}, \mathrm{Nd}, \mathrm{Hg}, \mathrm{Pb}$

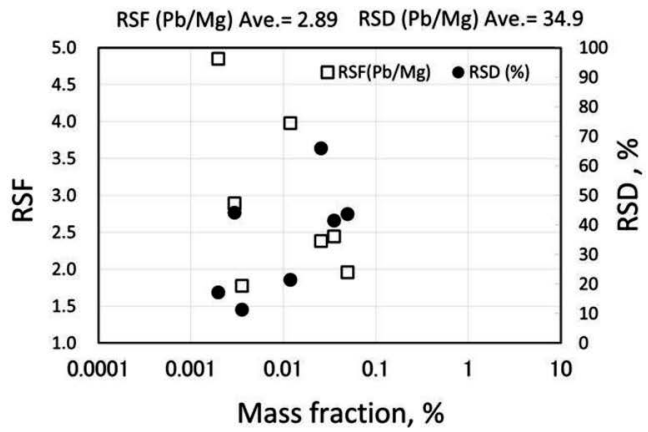

Fig. 3 Tendency of RSF values and RSD in Mg alloys. (a) Zn (typical element of RSD <15\%), (b) $\mathrm{Pb}$ (typical element of RSD $>15 \%$ ).

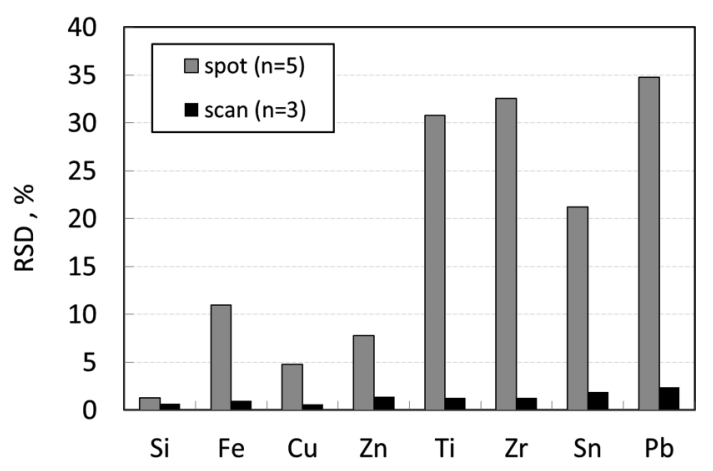

Fig. 4 Comparison of RSD of RSF values between vertical scans in same spot $(n=3)$ and different position of spots $(n=5)$ in $\mathrm{Al}$ alloy samples.

shown in Fig. 3(a) and for $\mathrm{Pb}$ in Fig. 3(b). $\mathrm{Al}, \mathrm{Si}, \mathrm{Ti}, \mathrm{Mn}$ and Fe could be listed as the same types of elements as $\mathrm{Zn}$, whose RSF values were steady and RSDs were below $15 \%$. However, dispersion of RSF values was entirely larger and the RSDs were higher than those in the $\mathrm{Al}$ matrix. The same tendency was recognized in the results for $\mathrm{Pb}$ with RSDs greater than $15 \%$. Yttrium, $\mathrm{Sn}, \mathrm{La}, \mathrm{Ce}, \mathrm{Nd}$, and $\mathrm{Hg}$ were classified into this group in the Mg matrix. The RSF values for these elements exhibit huge dispersion especially for the rare-earth elements such as $\mathrm{La}, \mathrm{Ce}$, and $\mathrm{Nd}$.

Figure 4 shows the difference between RSDs of RSF values during three scans in the vertical direction and RSDs in different spot positions $(n=5)$. While RSDs of RSF values for all elements obtained at the same spot are lower than 5\%, RSDs of $\mathrm{RSF}$ values for $\mathrm{Ti}, \mathrm{Zr}, \mathrm{Sn}$ and $\mathrm{Pb}$ from different spots become more than $15 \%$. These results imply that the large dispersion of RSF values for these elements should be due to differences of analysis position. The reason for the large dispersion of RSF is assumed to be the change of discharge conditions, including ionization of these elements and the horizontal localization of the elements depending on the position of the analyzed surface area.

In this work, the RSF value was assumed to have little dependence on the mass fraction of the element and the variation is assumed within uncertainty. All the RSF values obtained in the $\mathrm{Al}$ and $\mathrm{Mg}$ matrices are shown in Table 3. The standard
Table 3 The obtained RSF values of various elements in $\mathrm{Al}$ and $\mathrm{Mg}$ alloys in this work

\begin{tabular}{|c|c|c|c|c|c|c|}
\hline \multirow[b]{2}{*}{ Element } & \multicolumn{3}{|c|}{ Aluminum } & \multicolumn{3}{|c|}{ Magnesium } \\
\hline & $\begin{array}{c}\text { Measured } \\
\text { RSF }\end{array}$ & $\begin{array}{c}\mathrm{RSD}, \\
\%\end{array}$ & $\begin{array}{l}\text { Standard } \\
\text { RSF }\end{array}$ & $\begin{array}{c}\text { Measured } \\
\text { RSF }\end{array}$ & $\begin{array}{c}\mathrm{RSD}, \\
\%\end{array}$ & $\begin{array}{c}\text { Standard } \\
\text { RSF }\end{array}$ \\
\hline $\mathrm{Li}$ & 3.88 & 13 & 2.44 & & & \\
\hline $\mathrm{Be}$ & 1.80 & 9.2 & 3.97 & 1.62 & 20 & 3.34 \\
\hline B & 4.73 & 22 & 5.11 & & & \\
\hline $\mathrm{Na}$ & 1.28 & 6.1 & 0.75 & & & \\
\hline $\mathrm{Al}$ & & & 1.00 & 1.04 & 3.8 & 0.84 \\
\hline $\mathrm{Mg}$ & 1.25 & 3.0 & 1.19 & & & 1.00 \\
\hline $\mathrm{Si}$ & 1.45 & 3.0 & 2.39 & 0.95 & 4.8 & 2.01 \\
\hline $\mathrm{p}$ & 1.44 & 4.4 & 2.88 & & & \\
\hline $\mathrm{Ca}$ & 0.83 & 20 & 0.35 & 0.69 & 18 & 0.30 \\
\hline $\mathrm{Ti}$ & 0.67 & 24 & 0.32 & 1.64 & 11 & 0.27 \\
\hline V & 0.69 & 12 & 0.43 & & & \\
\hline $\mathrm{Cr}$ & 1.46 & 3.8 & 1.01 & & & \\
\hline $\mathrm{Mn}$ & 0.91 & 7.5 & 0.80 & 1.11 & 13 & 0.67 \\
\hline $\mathrm{Fe}$ & 0.74 & 6.2 & 0.79 & 0.85 & 14 & 0.66 \\
\hline $\mathrm{Co}$ & 0.81 & 4.7 & 0.82 & & & \\
\hline $\mathrm{Ni}$ & 1.06 & 4.6 & 1.19 & 1.18 & 5.0 & 1.00 \\
\hline $\mathrm{Cu}$ & 2.10 & 6.8 & 1.92 & 1.94 & 7.3 & 1.62 \\
\hline $\mathrm{Zn}$ & 1.70 & 7.6 & 3.02 & 2.13 & 9.4 & 2.54 \\
\hline Y & & & & 3.01 & 39 & 0.36 \\
\hline $\mathrm{Ga}$ & 1.56 & 4.7 & 1.84 & & & \\
\hline $\mathrm{Sr}$ & 1.29 & 69 & 0.41 & & & \\
\hline $\mathrm{Zr}$ & 0.92 & 22 & 0.44 & & & \\
\hline $\mathrm{Ag}$ & 1.94 & 3.9 & 3.03 & 2.41 & 9.3 & 2.55 \\
\hline $\mathrm{Cd}$ & 1.65 & 4.0 & 2.69 & 2.68 & 11 & 2.26 \\
\hline $\mathrm{Sn}$ & 1.41 & 15 & 1.02 & 2.21 & 20 & 0.85 \\
\hline $\mathrm{La}$ & & & & 5.21 & 60 & 0.42 \\
\hline $\mathrm{Ce}$ & & & & 5.48 & 59 & 0.50 \\
\hline $\mathrm{Nd}$ & & & & 6.21 & 61 & 0.58 \\
\hline $\mathrm{Hg}$ & & & & 4.47 & 20 & 2.89 \\
\hline $\mathrm{Sb}$ & 2.40 & 6.9 & 3.85 & & & \\
\hline $\mathrm{Pb}$ & 1.47 & 25 & 1.07 & 2.89 & 35 & 0.90 \\
\hline $\mathrm{Bi}$ & 2.21 & 13 & 2.31 & & & \\
\hline
\end{tabular}

RSF values recommended by the instrument producer ${ }^{9}$ are also shown for comparison. They were measured with discharge currents of $45 \mathrm{~mA}$ and an argon gas flow rate of $400 \mathrm{~mL} / \mathrm{min}$, using iron CRMs from NIST. A rather high discharge current of $72.5 \mathrm{~mA}$ and an argon gas flow rate of $450 \mathrm{ml} / \mathrm{min}$ are adopted to obtain the high sensitivity of ion detection in this work. 
Table 4 Analyzed values for Al alloy CRMs using obtained RSF values in this work (mass fraction, \%)

\begin{tabular}{|c|c|c|c|c|c|c|c|c|c|c|}
\hline Sample & & Element (isotope) & ${ }^{28} \mathrm{Si}$ & ${ }^{56} \mathrm{Fe}$ & ${ }^{63} \mathrm{Cu}$ & ${ }^{66} \mathrm{Zn}$ & ${ }^{47} \mathrm{Ti}$ & ${ }^{90} \mathrm{Zr}$ & ${ }^{208} \mathrm{~Pb}$ & ${ }^{117} \mathrm{Sn}$ \\
\hline \multirow[t]{4}{*}{$136 / 02$} & \multirow[t]{2}{*}{ Results } & Average & 0.25 & 0.3 & 0.049 & 0.04 & 0.02 & 0.006 & 0.002 & 0.002 \\
\hline & & Uncertainty $^{\mathrm{a}}$ & 0.001 & 0.02 & 0.001 & 0.001 & 0.003 & 0.0009 & 0.0002 & 0.0002 \\
\hline & \multirow[t]{2}{*}{ Certificate } & Value & 0.24 & 0.36 & 0.05 & 0.041 & 0.032 & 0.009 & 0.0024 & 0.0022 \\
\hline & & Uncertainty & 0.01 & 0.01 & 0.003 & 0.003 & 0.002 & 0.0005 & 0.0002 & 0.0002 \\
\hline \multirow[t]{4}{*}{$141 / 01$} & \multirow[t]{2}{*}{ Results } & Average & 0.41 & 0.3 & 0.022 & 0.01 & & & 0.005 & 0.005 \\
\hline & & Uncertainty $^{\mathrm{a}}$ & 0.003 & 0.02 & 0.001 & 0.001 & & & 0.0005 & 0.0004 \\
\hline & \multirow[t]{2}{*}{ Certificate } & Value & 0.41 & 0.4 & 0.02 & 0.014 & & & 0.01 & 0.01 \\
\hline & & Uncertainty & 0.02 & 0.01 & 0.001 & 0.0015 & & & 0.001 & 0.001 \\
\hline \multirow[t]{4}{*}{$533 / 03$} & \multirow[t]{2}{*}{ Results } & Average & 0.33 & 0.2 & 0.053 & 0.03 & 0.02 & 0.004 & 0.001 & 0.0009 \\
\hline & & Uncertainty $^{\mathrm{a}}$ & 0.003 & 0.01 & 0.001 & 0.002 & 0.002 & 0.0007 & 0.0003 & 0.0001 \\
\hline & \multirow[t]{2}{*}{ Certificate } & Value & 0.319 & 0.216 & 0.0544 & 0.0311 & 0.0188 & 0.0055 & 0.0022 & 0.0011 \\
\hline & & Uncertainty & 0.01 & 0.006 & 0.0015 & 0.0011 & 0.0009 & 0.0004 & 0.0002 & 0.0002 \\
\hline \multirow[t]{4}{*}{$636 / 02$} & \multirow[t]{2}{*}{ Results } & Average & 1.4 & 0.50 & 0.087 & 0.11 & 0.08 & 0.002 & 0.008 & 0.008 \\
\hline & & Uncertainty $^{\mathrm{a}}$ & 0.01 & 0.02 & 0.001 & 0.003 & 0.009 & 0.0002 & 0.0009 & 0.0007 \\
\hline & \multirow[t]{2}{*}{ Certificate } & Value & 1.387 & 0.576 & 0.0917 & 0.0997 & 0.1014 & 0.0032 & 0.0098 & 0.0095 \\
\hline & & Uncertainty & 0.042 & 0.020 & 0.0030 & 0.0030 & 0.0030 & 0.0004 & 0.0005 & 0.0005 \\
\hline
\end{tabular}

a. Uncertainty is calculated using the formula $u=\sigma_{\mathrm{n}-1} / \sqrt{n} ; \sigma_{\mathrm{n}-1}$, standard deviation; $n$, number of data $(n=5)$.

These differences of discharge conditions should affect the measured RSF values, and there are gaps between the measured RSF values and the standard RSF values, depending on the analyte elements. Because this variation has been discussed in the past few years, ${ }^{9,10}$ the RSF values should be quantitatively evaluated taking into account the discharge conditions, especially of discharge gas flow rate for further reliable analysis.

Four Al alloy CRMs were analyzed using the obtained average RSF values and the results were compared with the certified values, as shown in Table 4. Although some elements (Ti, Zr, $\mathrm{Pb}$, and $\mathrm{Sn}$ ) resulted in a larger $\mathrm{RSD}$ than $15 \%$, analytical values on the whole had good agreement with the certified values.

\section{Conclusions}

The RSF values in the case where the matrix elements are Al and $\mathrm{Mg}$ are determined by measuring CRMs by using a Grimmtype GDMS. The conclusions are listed below.

(1) The obtained RSF values have little dependence on the mass fraction of the analyte element and are almost steady. Two groups could be classified: one group has RSDs within $15 \%$ and shows good repeatability, and another has RSDs larger than $15 \%$ with relatively poor repeatability.

(2) Analytical results using the obtained average RSF values on the whole have good agreement with the certified values. However, for elements $\mathrm{Ti}, \mathrm{Zr}, \mathrm{Pb}$, and $\mathrm{Sn}$ (belonging in the group RSD >15\%), a large bias is recognized.

\section{References}

1. R. Kenneth Marcus and José A. C. Broekaert, "Glow Discharge Plasmas in Analytical Spectrometry", 2003, John Wiley \& Sons.

2. V. Hoffmann, M. Kasik, P. K. Robinson, and C. Venzago, Anal. Bioanal. Chem., 2005, 381, 173.

3. T. Gusarova, T. Hofmann, H. Kipphardt, C. Venzago, R. Matschat, and U. Panne, J. Anal. At. Spectrom., 2010, 25, 314.

4. W. Vieth and J. Huneke, Spectrochim. Acta, Part B, 1991, 46, 137.

5. C. Venzago, L. O. Pierrard, M. Kasik, U. Collisi, and S. Baude, J. Anal. At. Spectrom., 1998, 13, 189.

6. Nu Instruments Application Note, AN21, 2014.

7. ISO 6361-5, Wrought Aluminium and Aluminium AlloysSheets, Strips and Plates-Part 5: Chemical Composition, 2011.

8. ISO 16220, Magnesium and Magnesium Alloys-Magnesium Alloy Ingots and Castings, 2005.

9. T. Gusarova, T. Hofmann, H. Kipphardt, C. Venzago, R. Matschat, and U. Panne, J. Anal. At. Spectrom., 2010, 25, 314.

10. J. Hinrichs and S. Ducos, in Proceedings of the 2017 European Winter Conference on Plasma Spectrochemistry, 2017, 313. 